\title{
Mapping Trends and Hot-spots of Virtual Simulation Research in Nursing: A Bibliometric Analysis
}

\author{
Qian Zhang \\ Central South University \\ Jia Chen \\ Central South University \\ Jing Liu ( $D$ liujing_xyhl@csu.edu.cn ) \\ Central South University
}

\section{Research Article}

Keywords: virtual simulation, nursing, bibliometric analysis, hot-spots, Citespace, Vosviewer

Posted Date: December 15th, 2021

DOI: https://doi.org/10.21203/rs.3.rs-1038858/v2

License: (c) (1) This work is licensed under a Creative Commons Attribution 4.0 International License.

Read Full License 


\section{Abstract}

Background: Virtual simulation has been widely used in nursing education and nursing training. This study aims to characterize the publications in terms of countries, institutions, journals, authors, collaboration relationships, and analyze the trends of virtual simulation in nursing research.

Methods: Publications regarding virtual simulation in nursing were retrieved from Web of Science core collection. Microsoft Excel 2010, VOSviewer were used to characterize the contributions of the authors, journals, institutions, and countries. The trends, hot-spots and knowledge network were analyzed by Citespace and VOSviewer.

Results: We identified 611 papers between 1999 and 2021. The number of publications grew slowly until 2019, after that, it got a sharp increase in 2020 and 2021. The USA, Canada and Australia were three key contributors to this field. Centennial College, University of Ottawa, and Ryerson University were three major institutions with a larger number of publications. Verkuyl $\mathrm{M}$ was the most productive and highest cited author. Clinical Simulation in Nursing, Nurse Education Today, Journal of Nursing Education were the three productive journals. "virtual patients," "nursing students," "clinical simulation," and "communication skills" were the frontier topics in recent years.

Conclusion: Using the Virtual patients to train nursing students, developing more reliable and objective assessment methods to validate learning outcomes might be the recent and future hot-topics.

\section{Introduction}

Virtual simulation (VS) or virtual reality simulation is a computer system that creates and experiences the virtual world. Users can directly explore the role and changes of the simulated objects in the virtual environment, experience a sense of immersion[1]. In the last decades, nursing educators have increasingly used VS for nursing education and clinical training. For example, Girao[2]developed a serious virtual reality game for medication preparation and administration training. Weston, Jeannie[3] conducted a virtual simulation with clinical practice for pediatric nursing students during COVID-19 pandemic. Chao, YC [4] applied the immersive three-dimensional interactive video program to help nursing students better acquire nasogastric tube feeding skills. As a fast emerging area, there is an urgent need to investigate the research tendency and hot-spots in virtual simulation research in nursing.

Bibliometric analysis has been widely accepted to map the knowledge network and identify the trends in one certain field[5]. There are several existing bibliometric analysis about topics in nursing[6-8]. However, to the best of our knowledge, no study has focused on research tendency and hot-spots in VS in research nursing. Therefore, in this study, we utilized Citespace and Vosviewer $[9,10]$ to comprehensively analyze VS in nursing based on the Web of Science Core Collection (WoSCC). We hope this paper will uncover the development of VS in nursing field and predict possible progression in this field in the future.

\section{Materials \& Methods}




\subsection{Aims}

The aims of this study are as following: (1) to uncover the distributions and academic influence of different countries, institutions, journals, authors in virtual simulation related to nursing research. (2) to analyze the co-operation relationships in this field. (3) to map the knowledge network and identify the frontier topics in this field.

\subsection{Design}

A descriptive bibliometric analysis of publications in virtual simulation related to nursing research.

\subsection{Sample/Participants}

The data in this research were retrieved from Web of Science database, so no participants were involved.

\subsection{Search Strategy}

The advanced search was performed using Web of Science (Thomson Reuters, New York, USA) on August 1st, 2021. Formula: TS= ("virtual simulation" or "virtual reality" or "virtual reality simulation" or "virtual learning") and TS= ("nurs*") was used to screen out publications associated with VS in nursing. Two team members (Qian Zhang and Jing Liu) searched and screened the database independently. Any discrepancies were resolved by discussion with Jia Chen until consensus was reached.

\subsection{Inclusion criteria}

(1) Peer-reviewed articles involving VS related to nursing

(2) Original articles and review articles

(3) Written in English.

(4) Web of Science core collection (WoSCC).

\subsection{Exclusion Criteria}

(1) Unpublished papers

(2) Articles required a manual research.

\subsection{Data extraction and analysis}

The following bibliometric parameters were extracted, such as title, keywords, journal, publication year, citation counts, citations per year, $\mathrm{H}$-index, author, institution, country, and references. And then these data were imported into Microsoft Excel 2010 (Redmond, Washington, USA) to analyze the contributions of different countries, institutions, journals, and authors. VOSviewer (Leiden University, Leiden, the Netherlands) was applied to visualize the maps of coauthor-authorship, coauthor-institution, coauthorcountry, and keywords co-occurrence. In the VOSviewer map, node size indicates the number of articles produced. The wider links between nodes means stronger cooperation strength. The color means the 
average publication year for the node. Blue represents the early and yellow represents the late. Citespce(Version 5.8. R1) was used to identify the keywords burst and co-cited references burst [10].

\section{Results}

\subsection{General data}

An initial research of the WoSCC identified 783 publications. After excluded meeting abstract, early access and limited English language, 611 articles were finally enrolled into analysis. Original article accounts for 86 percent of the total $(n=523)$ (Figure 1). These papers were published from 1999 to 2021. The timing of publication could be divided into three periods (Phase I, 1999-2008; Phase Il, 2009-2019; Phase III, 2020-2021). 1999-2008, the number of articles per year was below 10 publications. 2009-2019, the annual output of this field has been increasing steadily to 59 publications. Since 2020 , it got a rapidly increased to 126 publications. The peak year was $2020(n=126)$. The total number of citations was 8606 , with 14 citations per paper and 374 citations per year (Figure 2A). The annual year publications of the top 10 countries were shown in Figure 2B.

\subsection{Active authors and co-cited authors}

The top 10 prolific authors in this area were all from North America (Table 1). Of them, there were eight from Canada, two from the USA. They published 95 papers and accounted for $15.5 \%$ of the total. Verkuyl M. from Centennial College was the most productive author in this scope with 18 publications. Followed by Luctkar-flude M from Queens University with 11 papers, and Tyerman J from University of Ottawa with 10 papers. In terms of co-cited author, Cook Da, Hoffman HG, and Verkuyl M were ranked the first three. Figure S1 showed the author cooperation network and co-cited author network. There were scattered cooperations between them. 
Table 1

Top 10 prolific authors and co-cited authors on virtual simulation research in nursing

\begin{tabular}{|llllllll|}
\hline Rank & Author & Publications & Citations & Country & $\begin{array}{l}\text { Co-cited } \\
\text { author }\end{array}$ & $\begin{array}{l}\text { Co- } \\
\text { citations }\end{array}$ & Country \\
\hline 1 & Verkuyl M & 18 & 173 & Canada & Cook, Da & 118 & USA \\
\hline 2 & $\begin{array}{l}\text { Luctkar- } \\
\text { flude M }\end{array}$ & 11 & 20 & Canada & $\begin{array}{l}\text { Hoffman, } \\
\text { HG }\end{array}$ & 108 & USA \\
\hline 3 & Tyerman J & 10 & 20 & Canada & Verkuyl, M & 103 & Canada \\
\hline 4 & Hughes M & 9 & 97 & Canada & Jeffries, Pr & 81 & USA \\
\hline 5 & $\begin{array}{l}\text { Romaniuk } \\
\text { D }\end{array}$ & 9 & 120 & Canada & $\begin{array}{l}\text { Inacsl } \\
\text { Stand, }\end{array}$ & 64 & N/A \\
\hline 6 & Farra S & 8 & 115 & USA & Cant, Rp & 62 & Australia \\
\hline 7 & Lapum JL & 8 & 85 & Canada & Foronda, Cl & 60 & USA \\
\hline 8 & Mastrilli P & 8 & 112 & Canada & Foronda, C & 59 & USA \\
\hline 9 & Hodgson E & 7 & 89 & USA & Liaw, Sy & 49 & Singapore \\
\hline 10 & St-amant O & 7 & 46 & Canada & Hayden, Jk & 45 & USA \\
\hline
\end{tabular}

\subsection{Active journals and co-cited journals}

The top 10 active and co-cited journals were identified by VOSviewer. Altogether, 260 journals contributed to VS in nursing. The top 10 productive journals published 247(39.3\%) papers. Clinical Simulation in Nursing was the most productive journal $(n=92)$, followed by Nurse Education Today $(n=48)$ and Journal of Nursing Education $(n=24)$. The top three co-cited journals were the same journals as mentioned above, with $820,667,339$ co-citations, respectively (Table2). 
Table 2

Top 10 prolific journals and co-cited journals on virtual simulation research in nursing

\begin{tabular}{|c|c|c|c|c|c|c|c|}
\hline Rank & Journal & Publications & Citations & $\mathrm{IF}^{*}$ & $\begin{array}{l}\text { Co-cited } \\
\text { journal }\end{array}$ & $\begin{array}{l}\text { Co- } \\
\text { citations }\end{array}$ & IF \\
\hline 1 & $\begin{array}{l}\text { Clinical } \\
\text { Simulation in } \\
\text { Nursing }\end{array}$ & 92 & 735 & 2.391 & $\begin{array}{l}\text { Clinical } \\
\text { Simulation in } \\
\text { Nursing }\end{array}$ & 820 & 2.391 \\
\hline 2 & $\begin{array}{l}\text { Nurse Education } \\
\text { Today }\end{array}$ & 48 & 509 & 3.442 & $\begin{array}{l}\text { Nurse } \\
\text { Education } \\
\text { Today }\end{array}$ & 667 & 3.442 \\
\hline 3 & $\begin{array}{l}\text { Journal of } \\
\text { Nursing } \\
\text { Education }\end{array}$ & 24 & 206 & 1.726 & $\begin{array}{l}\text { Journal of } \\
\text { Nursing } \\
\text { Education }\end{array}$ & 339 & 1.726 \\
\hline 4 & $\begin{array}{l}\text { Journal of } \\
\text { Medical Internet } \\
\text { Research }\end{array}$ & 18 & 401 & 5.428 & $\begin{array}{l}\text { Nursing } \\
\text { Education } \\
\text { Perspectives }\end{array}$ & 256 & N/A \\
\hline 5 & $\begin{array}{l}\text { Nurse Education } \\
\text { in Practice }\end{array}$ & 17 & 216 & 2.281 & $\begin{array}{l}\text { Medical } \\
\text { Education }\end{array}$ & 232 & 6.251 \\
\hline 6 & Nurse Educator & 13 & 140 & 2.082 & $\begin{array}{l}\text { Medical } \\
\text { Teacher }\end{array}$ & 212 & 3.65 \\
\hline 7 & $\begin{array}{l}\text { Cin Computers } \\
\text { Informatics } \\
\text { Nursing }\end{array}$ & 11 & 99 & 1.985 & $\begin{array}{l}\text { Journal of } \\
\text { Medical } \\
\text { Internet } \\
\text { Research }\end{array}$ & 210 & 5.428 \\
\hline 8 & Burns & 8 & 289 & 2.744 & $\begin{array}{l}\text { Simulation in } \\
\text { Healthcare }\end{array}$ & 206 & 1.929 \\
\hline 9 & $\begin{array}{l}\text { Journal of } \\
\text { Clinical Nursing }\end{array}$ & 8 & 165 & 3.036 & $\begin{array}{l}\text { Nurse } \\
\text { Education in } \\
\text { Practice }\end{array}$ & 197 & 2.281 \\
\hline 10 & $\begin{array}{l}\text { Nursing } \\
\text { Education } \\
\text { Perspectives }\end{array}$ & 8 & 62 & N/A & $\begin{array}{l}\text { Academic } \\
\text { Medicine }\end{array}$ & 194 & 6.892 \\
\hline
\end{tabular}

\subsection{Active institutions.}

The top 10 most productive institutions were presented in Figure 3A. Among the top 10 institutions, there were five located in Canada, four in the USA, and one in Singapore. Centennial College was the most prolific institution ( $n=17$ publications), followed by University of Ottawa and Ryerson University. In terms of citations and H-index, University of Toronto (Canada, 576 citations, $9 \mathrm{H}$-index), University of Ottawa (Canada, 329 citations, $8 \mathrm{H}$-index), Centennial College (Canada, 173 citations, $7 \mathrm{H}$-index) ranked in the top three. The co-authorship for organization module in VOSviewer was used to visualize the collaboration 
relationship among 39 institutions, which published at least 5 papers. As shown in Figure 3B, There were few and sporadic connecting lines between different institutions.

\subsection{Active countries/regions}

A total of 58 countries/regions participated in these publications. The top 10 were shown in Figure 4A. Obviously, the USA led in this field with 250 publications ( $40.9 \%$ of the total), 4289 citations, and $34 \mathrm{H}$ index. The module of co-authorship for country in VOSviewer was used to map the country cooperations network. The smallest number of publications was settled as five. Finally, 26 countries meet our criterion. The USA, Canada, Australia, and England presented as the largest node. The strongest cooperation was between the USA and Canada and between the USA and Australia (Figure 4B).

\subsection{Keywords}

High-frequency keywords was usually used to describe hot-spots, and construct a knowledge map[11]. Thesaurus was applied to clean out similar keywords. For example, virtual reality simulation and virtual reality were replaced by VS. We identified 1459 keywords in total, 72 keywords occurred more than five times were enrolled into analysis. The top five keywords ranked by number of occurrences were: virtual simulation ( $n=406)$, education $(n=131)$, nurse education $(n=106)$, nursing $(n=65)$, skills $(n=59)$. As shown in Figure 5A, the keywords were classified into five clusters. Cluster one (red) referred to pain and anxiety management, the primary keywords were "virtual simulation, anxiety, children." Cluster two (green) referred to virtual patients, the primary keywords were "nurse education, skills, nursing students, virtual patients." Cluster three (blue) referred to clinical simulation training, the primary keywords were "nursing, clinical simulation, simulation training, gaming." Cluster four (yellow) and Cluster five (purple) referred to non-technical-skills, the primary keywords included "performance, communication, impact, surgery, patient, nurses, environments, patient simulation." As shown in Figure 5B, keywords were colored by VOSviewer according to their average publication years. During the early phase, "virtual patients, pain, and distraction" were the primary focus in this field. Recently, the trend has shifted to "nurse education, clinical simulation, and communication skills". Also, Citespace burst module were used to identify the research trends and frontier topics[12]. The burst duration was set to 2 years. The blue and red bar indicated infrequently and frequently cited time. The top 19 keywords with strongest citation bursts were auto-identified and displayed in Figure 5C. Among them, virtual patient has the highest burst strength $(n=4.09)$. During the early stage, "distraction, adolescent, medical education" were the primary topic. More recently, 2015 to 2021, the following topics, such as program, rehabilitation, balance, nursing education, and reality attracted more attention.

\subsection{Top cited articles and co-cited references}

The top 10 most cited articles were listed in Table 3. To date, the most cited article was by Cook, David A[13] published in Academic Medicine by 2010 with 246 citations, entitled computerized virtual patients 
in health professions education: a systematic review and meta-analysis. The co-cited references were the article which cited by the included papers of VS in nursing. The top 17 co-cited references were identified through 18420 references which co-cited more than 20 times by the included 611 papers. As shown in Figure 6A, the article with highest link strength was published by Foronda, Cynthia[14] in Nurse Education Today in 2014, entitled use of virtual clinical simulation to improve communication skills of baccalaureate nursing students: a pilot study. Similarly, CiteSpace citation burst could identify references focused by researchers in a specific period $[9,15]$. The burst duration was set to 2 years. At last, 23 references with strongest citation bursts were identified in Figure 6B. Among them, Kidd Li, 2012, J PSYCHOSOC NURS MEN, V50, P28[16] had the highest burst strength $(n=7.21)$. Articles with citation bursts ending in 2021 were: "Kyaw BM, 2019, J MED INTERNET RES, V21, P0[17]", "Liaw SY, 2014, J MED INTERNET RES, V16, P0[18]," and "Smith PC, 2015, CLIN SIMUL NURS, V11, P52[19]." Kyaw BM performed a meta-analysis study and found virtual reality could improve the knowledge and skills of health professionals compared with traditional education or digital education[17]. Liaw S Y conducted a randomized controlled trial and found that although there were no significant differences in improving nursing students' clinical performance, virtual simulations were more convenient and promising than mannequin-based simulations[18]. Smith PC designed a virtual reality simulation to evaluate Foley catheter skill proficiency in nursing students, and found virtual reality simulation could be a supplemental tool for teaching students critical steps in clinical skills[19]. 
Table 3

Top10 most cited papers related to virtual simulation research in nursing

\begin{tabular}{|c|c|c|c|c|c|}
\hline Rank & Title & Author & Journal & Year & $\begin{array}{l}\text { Total } \\
\text { Citations }\end{array}$ \\
\hline 1 & $\begin{array}{l}\text { Computerized Virtual Patients in } \\
\text { Health Professions Education: A } \\
\text { Systematic Review and Meta- } \\
\text { Analysis }\end{array}$ & $\begin{array}{l}\text { Cook, } \\
\text { David A. }\end{array}$ & $\begin{array}{l}\text { Academic } \\
\text { Medicine }\end{array}$ & 2010 & 246 \\
\hline 2 & $\begin{array}{l}\text { Mastery Learning for Health } \\
\text { Professionals Using Technology- } \\
\text { Enhanced Simulation: A Systematic } \\
\text { Review and Meta-Analysis }\end{array}$ & $\begin{array}{l}\text { Cook, } \\
\text { David A. }\end{array}$ & $\begin{array}{l}\text { Academic } \\
\text { Medicine }\end{array}$ & 2013 & 153 \\
\hline 3 & $\begin{array}{l}\text { Evaluation of trauma team } \\
\text { performance using an advanced } \\
\text { human patient simulator for } \\
\text { resuscitation training }\end{array}$ & $\begin{array}{l}\text { Holcomb, } \\
\text { JB }\end{array}$ & $\begin{array}{l}\text { Journal of } \\
\text { Trauma-Injury } \\
\text { Infection And } \\
\text { Critical Care }\end{array}$ & 2002 & 152 \\
\hline 4 & $\begin{array}{l}\text { A pilot and feasibility study of } \\
\text { virtual reality as a distraction for } \\
\text { children with cancer }\end{array}$ & Gershon, J & $\begin{array}{l}\text { Journal of The } \\
\text { American } \\
\text { Academy of } \\
\text { Child And } \\
\text { Adolescent } \\
\text { Psychiatry }\end{array}$ & 2004 & 151 \\
\hline 5 & $\begin{array}{l}\text { Current trends in stroke } \\
\text { rehabilitation. A review with focus } \\
\text { on brain plasticity }\end{array}$ & $\begin{array}{l}\text { Johansson, } \\
\text { B. B. }\end{array}$ & $\begin{array}{l}\text { Acta Neurologica } \\
\text { Scandinavica }\end{array}$ & 2011 & 149 \\
\hline 6 & $\begin{array}{l}\text { Patient Outcomes in Simulation- } \\
\text { Based Medical Education: A } \\
\text { Systematic Review }\end{array}$ & $\begin{array}{l}\text { Zendejas, } \\
\text { B. }\end{array}$ & $\begin{array}{l}\text { Journal of } \\
\text { General Internal } \\
\text { Medicine }\end{array}$ & 2013 & 148 \\
\hline 7 & $\begin{array}{l}\text { Effects of distraction on pain, fear, } \\
\text { and distress during venous port } \\
\text { access and venipuncture in children } \\
\text { andAdolescents with cancer }\end{array}$ & $\begin{array}{l}\text { Windich- } \\
\text { Biermeier, } \\
\text { A. }\end{array}$ & $\begin{array}{l}\text { Journal of } \\
\text { Pediatric } \\
\text { Oncology } \\
\text { Nursing }\end{array}$ & 2007 & 127 \\
\hline 8 & $\begin{array}{l}\text { Intravenous catheter training } \\
\text { system: Computer-based education } \\
\text { versus traditional learning methods }\end{array}$ & Engum, SA. & $\begin{array}{l}\text { American } \\
\text { Journal of } \\
\text { Surgery }\end{array}$ & 2003 & 123 \\
\hline 9 & $\begin{array}{l}\text { The Insertion and Management of } \\
\text { External Ventricular Drains: An } \\
\text { Evidence-Based Consensus } \\
\text { Statement }\end{array}$ & $\begin{array}{l}\text { Fried, } \\
\text { Herbert I. }\end{array}$ & $\begin{array}{l}\text { Neurocritical } \\
\text { Care }\end{array}$ & 2016 & 120 \\
\hline 10 & $\begin{array}{l}\text { A randomized trial of teaching } \\
\text { clinical skills using virtual and live } \\
\text { standardized patients }\end{array}$ & Triola, M. & $\begin{array}{l}\text { Journal of } \\
\text { General Internal } \\
\text { Medicine }\end{array}$ & 2006 & 116 \\
\hline
\end{tabular}

Virtual patient had the strongest burst citations and last from 2012 to 2019. Nursing education colored yellow in VOSviewer keyword network and had a moderate burst strength in 2021. Therefore, we choose virtual patient and nurse education as hot topics in recent years. 


\section{Discussion}

This study, we mapped a knowledge network of VS in nursing research from 1999 to 2021. Meanwhile, we analyzed the contributions of different authors, journals, institutions, and countries. The number of publications in a field reflects the activity and productivity over the years[15]. The overall trend of publication in this filed was upward, and could divided into three phases. Before 2008, the number of articles per year slightly increased. It may be restricted by technology such as internet access or computer popularity. Likewise, previous study found before the year of 2005, the applications of virtual patient in medical education were small[20]. Since 2020, the number of papers got a sharp increase. We speculate several reasons account for this. First, because of social isolation during the COVID-19 pandemic, educators were forced to change the way of program delivery [21]. Numerous online programs has emerged during the COVID-19, such as virtual lab environments[22], three-dimensional virtual world (3DVW)[23], personal protective equipment (PPE) virtual simulation games[24]. Such VS programs effectively enhanced nursing student interest and provided nurse educators with novel and engaging means of content delivery[21]. Second, COVID-19 pandemic accelerated the demand for more nursing staff and higher quality nursing care. Indeed, not all nurses or medical staff have the chance to face such an outbreak. It is difficult to educate and train these back-ups with any physical touch. However, the greatest strength of VS could provide an almost real environment that simulated any emergency in COVID-19. It is perfect to solve this problem.

Without surprising, the USA leads the VS in nursing research, which requires the collaboration of multiple disciplines, such as medical informatics, education, computer science, and software engineering. Other areas displayed the similar leading position of the USA, such as radiation-induced lung injury [25], and human-computer interaction[26], etc. Interestingly, in terms of the number of productive authors and institutions, Canada ranked ahead of the USA. Extensively studies showed that collaborations tends to be stronger between institutions or countries with shorter geographical distances[7]. We speculated the cooperation links between authors and institutions within Canada were stronger than that in the USA. As expected, Figure S1 and Figure 4B further corroborated our hypothesis. There are scattered links between numerous American authors and institutions, but relative close relationships between Canadian authors and institutions. Considering the scattered collaborations in this field, we hope there will be more interinstitutions and international research in the future.

Key journals, institutions, and authors provide the essential information for a given field. Clinical Simulation in Nursing, Nurse Education Today, and Journal of Nursing Education are the top three productive and co-cited journals. Researchers should continue to pay particular attention on them, because some frontier articles may be published in these journals. In addition, researchers could choose these journals for their draft submission. Institutions like Centennial College, University of Toronto, University of Ottawa, and scholars like Verkuyl M, Luctkar-flude M, Tyerman J, Cook Da, and Hoffman, HG should be followed and maybe the potential cooperation partner. 
Keyword network and references analysis facilitates researchers to get insight into a certain field quickly[10]. We found the keywords with largest node size were following areas: virtual simulation, nurse education, and skills. Moreover, from the color assigned to keywords by VOSviewer, the trend shifted to nurse education, students, clinical simulation, and communication skills. They all indicated that virtual simulation for nursing teaching is a hot topic in current research. Basically, one of the principles of registered nurses is "do no harm" to patients [27]. However, the traditional apprenticeship learning model does not ensure nurses' acquisition of adequate theory and practical skills before handling the clinical workplace [28]. Therefore, 3D virtual environment such as second Life laboratory to practice the students' experience of learning decision-making skills and communication skills got considerable attention in recent years[29-32]. More importantly, the advanced VS program, virtual patients, was developed to provide numerous realistic standard clinical situations to train the students' skills, like clinical reasoning[33-35], communication skills[36-38], situation awareness, and teamwork capability[39] which paved the way of the medical education into a new era. But we should noticed that while studies have shown the positive feedback of VS in nursing education, previous research has largely overlooked the significance of assessment methods of learning outcomes. Currently, the predominant methods for assessing learning outcomes are combinations of paper-based exams and observations from clinical teachers[40], effective and objective assessment methods related to learning outcomes are still lacking[41-43]. Despite Carina,Georg[44]developed the modified visual patient Lasater Clinical Judgment Rubric (vpLCJR) to evaluate nursing students' clinical reasoning, limited studies investigated the method of assessing outcome of nursing students' non-technical skills.

\subsection{Limitations}

First, the papers on VS in nursing were searched based on the WoSCC. Although WoSCC is recognized as one of the most authoritative databases, PubMed, Scopus, and Google scholar are also widely accepted by scientists. Second, the number of citations and $\mathrm{H}$-index are influenced by time and remain controversial as a comprehensive indicator of the quality of one paper or the author. Likewise, the larger number of publications was not the only indicator of influence for the journal, as other indicators (e.g., impact factor, SNIP, CiteScore, SJR) are widely accepted[45]. Third, we included only English papers in this study, several papers with non-English languages were excluded, such as Chinese, Japanese, and Russian. Finally, the published articles in 2021 only include the first seven months, and database updates may result in discrepancies. However, we believe that the low citation frequency of new publications has less impact on our conclusions.

\section{Conclusions}

This bibliometric analysis mapped the knowledge network of virtual simulation in nursing research. Further work should strengthen the co-operation between authors, institutions, and countries. Using the Virtual patients to train nursing students, developing more reliable and objective assessment methods to validate learning outcomes might be the recent and future hot-topics. 


\section{Abbreviations}

WoSCC: Web of Science Core Collection

VS: virtual simulation

IF: impact factor

\section{Declarations}

\section{Ethics approval and consent to participate}

Not applicable

\section{Consent for publication}

Not applicable

\section{Availability of data and materials}

The datasets used and/or analysed in this study are available from the corresponding author on reasonable request

\section{Competing interests}

The authors declare no competing of interest.

\section{Funding}

This study was supported by the Hunan Science and Technology Innovation Platform and Talent Plan [Grant: 2017TP1004].

\section{Authors' contributions}

Z.Q. conceived of the study, participated in its design, obtained data and drafted the manuscript.

L.J. involved in study design, obtained data and contributed to interpretation, and helped to draft the manuscript. C.J. provided the theoretical frameworks and performed much of the editing of the manuscript. All authors read and approved the final manuscript. 


\section{Acknowledgements}

None

\section{References}

1. Kilmon CA, Brown L, Ghosh S, Mikitiuk A: Immersive virtual reality simulations in nursing education. Nursing education perspectives 2010, 31(5):314-317.

2. Girao ALA, Dos Santos MNO, Chaves EMC, Gomes EB, de Oliveira SKP, de Carvalho REFL: NurseVR: Development of a Serious Virtual Reality Game for Medication Preparation and Administration Training. Computers, informatics, nursing : CIN2021.

3. Weston J, Zauche LH: Comparison of Virtual Simulation to Clinical Practice for Prelicensure Nursing Students in Pediatrics. Nurse Educator 2021, 46(5):E95-E98.

4. Chao YC, Hu SH, Chiu HY, Huang PH, Tsai HT, Chuang YH: The effects of an immersive 3d interactive video program on improving student nurses' nursing skill competence: A randomized controlled trial study. Nurse Education Today 2021, 103.

5. Tan Y, Yu Q, Ma L, Chang J, Zhan X, Cui H, Liu Y, Sui Y: A bibliometric analysis of the application of procalcitonin in patients in the intensive care unit. Annals of palliative medicine 2021, 10(6):63676378.

6. Taskaya S, Aksoy A: A bibliometric analysis of workplace incivility in nursing. J Nurs Manag 2021, 29(3):518-525.

7. Yanbing S, Hua L, Chao L, Fenglan W, Zhiguang D: The state of nursing research from 2000 to 2019: A global analysis. Journal of advanced nursing 2021, 77(1):162-175.

8. Jarden R, Narayanan A, Sandham M, Siegert R, Koziol-McLain J: Bibliometric mapping of intensive care nurses' wellbeing: development and application of the new iAnalysis model. BMC nursing 2019, 18:21.

9. Chen CM: CiteSpace II: Detecting and visualizing emerging trends and transient patterns in scientific literature. Journal of the American Society for Information Science and Technology 2006, 57(3):359377.

10. van Eck NJ, Waltman L: Software survey: VOSviewer, a computer program for bibliometric mapping. Scientometrics 2010, 84(2):523-538.

11. Liao HC, Tang M, Luo L, Li CY, Chiclana F, Zeng XJ: A Bibliometric Analysis and Visualization of Medical Big Data Research. Sustainability 2018, 10(1).

12. Dong J, Wei W, Wang C, Fu Y, Li Y, Li J, Peng X: Research trends and hotspots in caregiver studies: A bibliometric and scientometric analysis of nursing journals. Journal of advanced nursing 2020 , 76(11):2955-2970.

13. Cook D, Erwin P, Triola M: Computerized virtual patients in health professions education: a systematic review and meta-analysis. Academic medicine : journal of the Association of American 
Medical Colleges 2010, 85(10):1589-1602.

14. Foronda C, Gattamorta K, Snowden K, Bauman EB: Use of virtual clinical simulation to improve communication skills of baccalaureate nursing students: a pilot study. Nurse education today 2014, 34(6):e53-57.

15. Chen D, Zhang G, Wang J, Chen S, Wang J, Nie H, Tang Z: Mapping Trends in Moyamoya Angiopathy Research: A 10-Year Bibliometric and Visualization-Based Analyses of the Web of Science Core Collection (WoSCC). Frontiers in neurology 2021, 12:637310.

16. Kidd L, Knisley S, Morgan K: Effectiveness of a second life(®) simulation as a teaching strategy for undergraduate mental health nursing students. Journal of psychosocial nursing and mental health services 2012, 50(7):28-37.

17. Kyaw B, Saxena N, Posadzki P, Vseteckova J, Nikolaou C, George P, Divakar U, Masiello I, Kononowicz A, Zary N et al: Virtual Reality for Health Professions Education: Systematic Review and MetaAnalysis by the Digital Health Education Collaboration. Journal of medical Internet research 2019, 21(1):e12959.

18. Liaw S, Chan S, Chen F, Hooi S, Siau C: Comparison of virtual patient simulation with mannequinbased simulation for improving clinical performances in assessing and managing clinical deterioration: randomized controlled trial. Journal of medical Internet research 2014, 16(9):e214.

19. Smith PC, Hamilton BK: The Effects of Virtual Reality Simulation as a Teaching Strategy for Skills Preparation in Nursing Students. Clinical Simulation in Nursing 2015, 11(1):52-58.

20. Su W-S, Chang C-Y: Virtual patient in interactive learning environments: a review of 1989-2020 publications in selected SSCI journals. INTERACTIVE LEARNING ENVIRONMENTS.

21. Saab MM, Hegarty J, Murphy D, Landers M: Incorporating virtual reality in nurse education: A qualitative study of nursing students' perspectives. Nurse Education Today 2021, 105:7.

22. Cantey DS, Sampson M, Vaughn J, Blodgett NP: Skills, community, and rapport: Prelicensure nursing students in the virtual learning environment. Teach Learn Nurs 2021, 16(4):384-388.

23. Liaw SY, Choo T, Wu LT, Lim WS, Choo H, Lim SM, Ringsted C, Wong LF, Ooi SL, Lau TC: Wow, woo, win"- Healthcare students' and facilitators' experiences of interprofessional simulation in threedimensional virtual world: A qualitative evaluation study. Nurse Education Today 2021, 105:6.

24. Tyerman J, Luctkar-Flude M, Baker C: Rapid Development of a COVID-19 Assessment and PPE Virtual Simulation Game. Clinical Simulation in Nursing 2021, 56:125-132.

25. Wang D, Li Z, Zhang Y, Li Y, Wang X, Wang S, Gui Y, Dong J, Hou W: Bibliometric analysis of research relating to radiation-induced lung injury (2001-2020). Annals of palliative medicine 2021.

26. Wang J, Cheng R, Liu M, Liao P: Research Trends of Human-Computer Interaction Studies in Construction Hazard Recognition: A Bibliometric Review. Sensors (Basel, Switzerland) 2021, 21(18).

27. Sutcliffe H: Understanding the NMC code of conduct: a student perspective. Nursing standard (Royal College of Nursing (Great Britain) : 1987) 2011, 25(52):35-39. 
28. Nicol M, Glen S: Learning clinical skills: the return of the practical room? Nurse education today 1998, 18(6):427-428.

29. Jenson C, Forsyth $D$ : Virtual reality simulation: using threedimensional technology to teach nursing students. Computers, informatics, nursing : CIN2012, 30(6):312-318; quiz 319-320.

30. McCallum J, Ness V, Price T: Exploring nursing students' decision-making skills whilst in a Second Life clinical simulation laboratory. Nurse education today 2011, 31(7):699-704.

31. Wiecha J, Heyden R, Sternthal E, Merialdi M: Learning in a virtual world: experience with using second life for medical education. Journal of medical Internet research 2010, 12(1):e1.

32. Bahrami M, Hadadgar A, Fuladvandi M: Designing Virtual Patients for Education of Nursing Students in Cancer Course. Iranian journal of nursing and midwifery research 2021, 26(2):133-136.

33. Forsberg E, Georg C, Ziegert K, Fors U: Virtual patients for assessment of clinical reasoning in nursing - a pilot study. Nurse education today 2011, 31(8):757-762.

34. Forsberg $\mathrm{E}$, Ziegert $\mathrm{K}$, Hult $\mathrm{H}$, Fors $\mathrm{U}$ : Clinical reasoning in nursing, a think-aloud study using virtual patients - a base for an innovative assessment. Nurse education today 2014, 34(4):538-542.

35. Everett-Thomas R, Joseph L, Trujillo G: Using virtual simulation and electronic health records to assess student nurses' documentation and critical thinking skills. Nurse education today 2021, 99:104770.

36. Shorey S, Ang E, Ng E, Yap J, Lau L, Chui C: Communication skills training using virtual reality: $\mathbf{A}$ descriptive qualitative study. Nurse education today 2020, 94:104592.

37. Shorey S, Ang E, Yap J, Ng E, Lau S, Chui C: A Virtual Counseling Application Using Artificial Intelligence for Communication Skills Training in Nursing Education: Development Study. Journal of medical Internet research 2019, 21(10): 1 14658.

38. Chapelain P, Morineau T, Gautier C: Effects of communication on the performance of nursing students during the simulation of an emergency situation. Journal of advanced nursing 2015 , 71(11):2650-2660.

39. Peddle M, Mckenna L, Bearman M, Nestel D: Development of non-technical skills through virtual patients for undergraduate nursing students: An exploratory study. Nurse education today 2019, 73:94-101.

40. Stayt $L$, Merriman $C$, Ricketts $B$, Morton S, Simpson T: Recognizing and managing a deteriorating patient: a randomized controlled trial investigating the effectiveness of clinical simulation in improving clinical performance in undergraduate nursing students. Journal of advanced nursing 2015, 71(11):2563-2574.

41. Cook DA, Triola MM: Virtual patients: a critical literature review and proposed next steps. Med Educ 2009, 43(4):303-311.

42. Ward R, Muckle T, Kremer M, Krogh M: Computer-Based Case Simulations for Assessment in Health Care: A Literature Review of Validity Evidence. Evaluation \& the health professions 2019, 42(1):82102. 
43. Chen S, Huang T, Liao I, Liu C: Development and validation of the Simulation Learning Effectiveness Inventory. Journal of advanced nursing 2015, 71(10):2444-2453.

44. Georg C, Karlgren K, Ulfvarson J, Jirwe M, Welin E: A Rubric to Assess Students' Clinical Reasoning When Encountering Virtual Patients. The Journal of nursing education 2018, 57(7):408-415.

45. Mingers J, Yang LY: Evaluating journal quality: A review of journal citation indicators, and ranking in business and management. Eur J Oper Res 2017, 257(1):323-337.

\section{Figures}

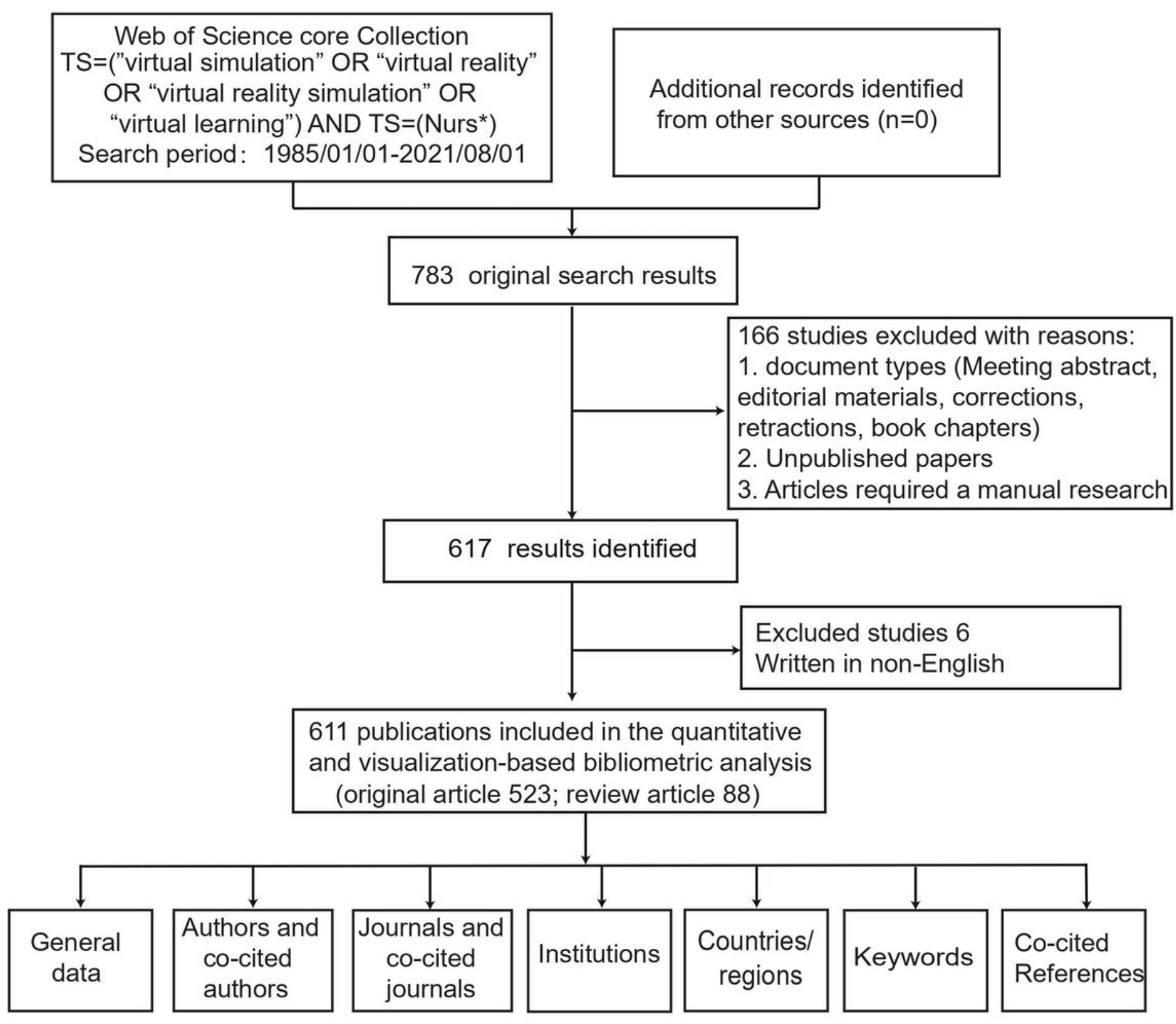

Figure 1

Flow chart of data screening and bibliometric analysis 

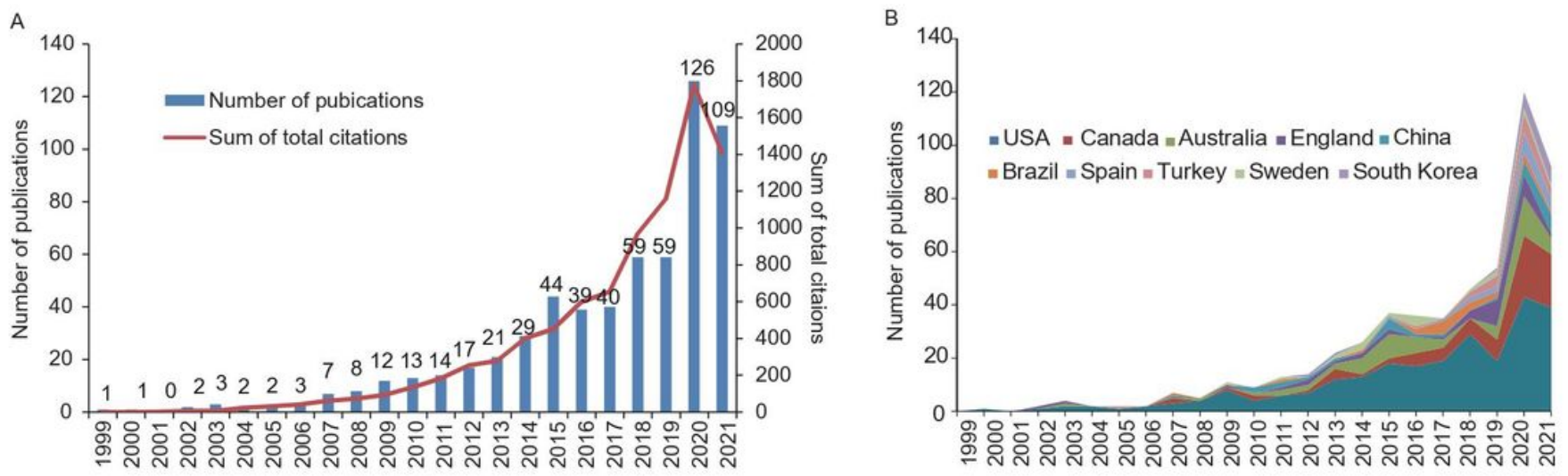

\section{Figure 2}

The number of publications and total citations related to virtual simulation in nursing studies. (A) The number of papers published and total citations each year. (B) The top 10 countries/regions annual publications.

A

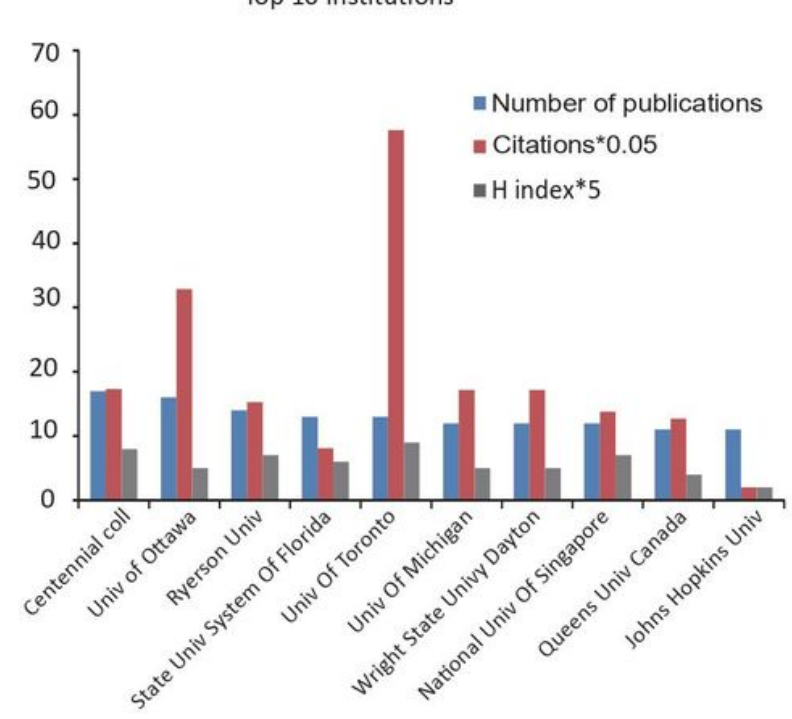

B

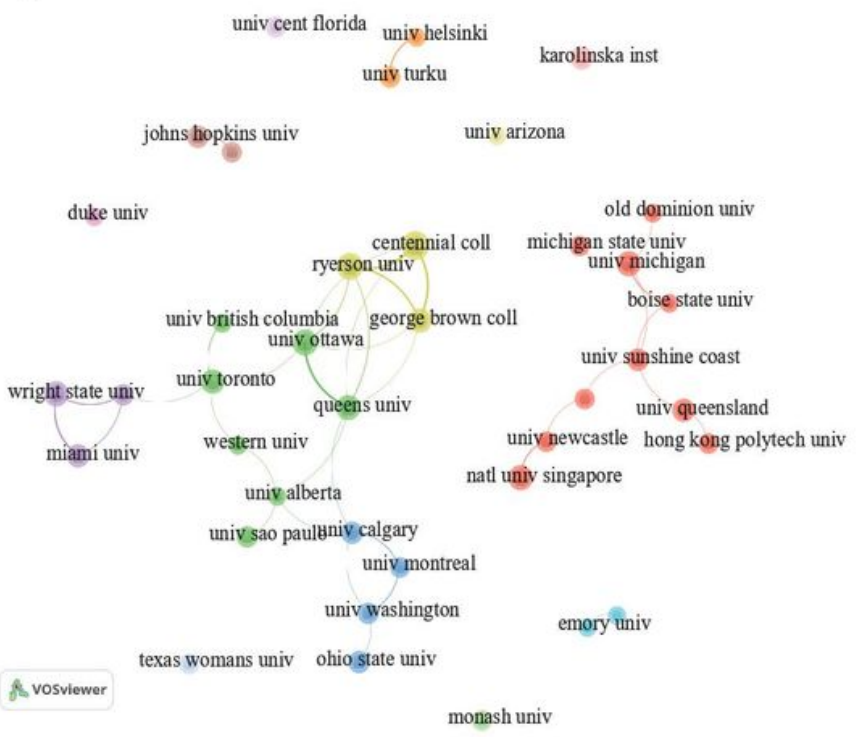

\section{Figure 3}

The top 10 most productive institutions and inter-institution cooperation relationships on virtual simulation research in nursing. (A) The number of publications, citation frequency $(\times 0.05)$, and $\mathrm{H}$-index $(\times 5)$ in top 10 institutions. (B) The co-authorship network visualization map of institution for virtual simulation in nursing research. Node size indicated the number of articles produced. The distance between any two nodes positively associated with the cooperation strength. 
A

Top 10 Countries

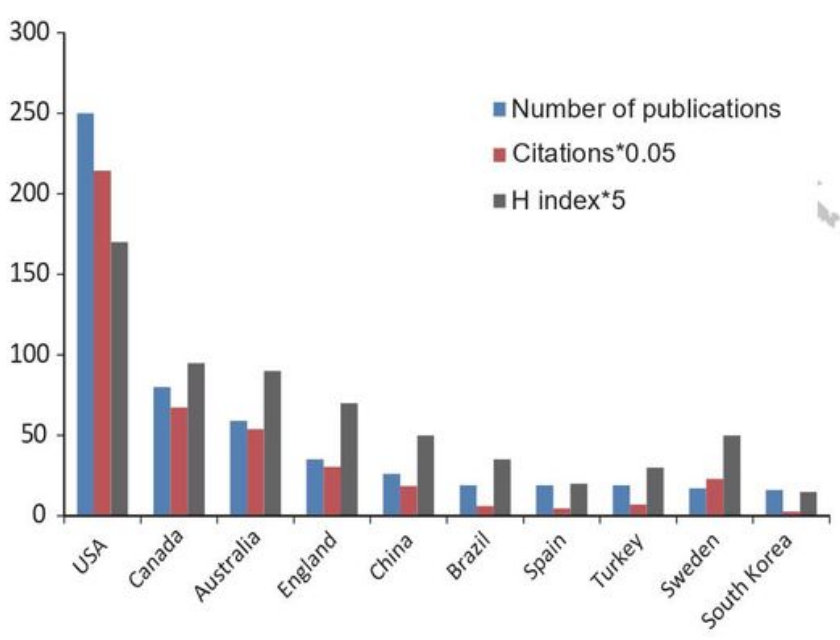

B

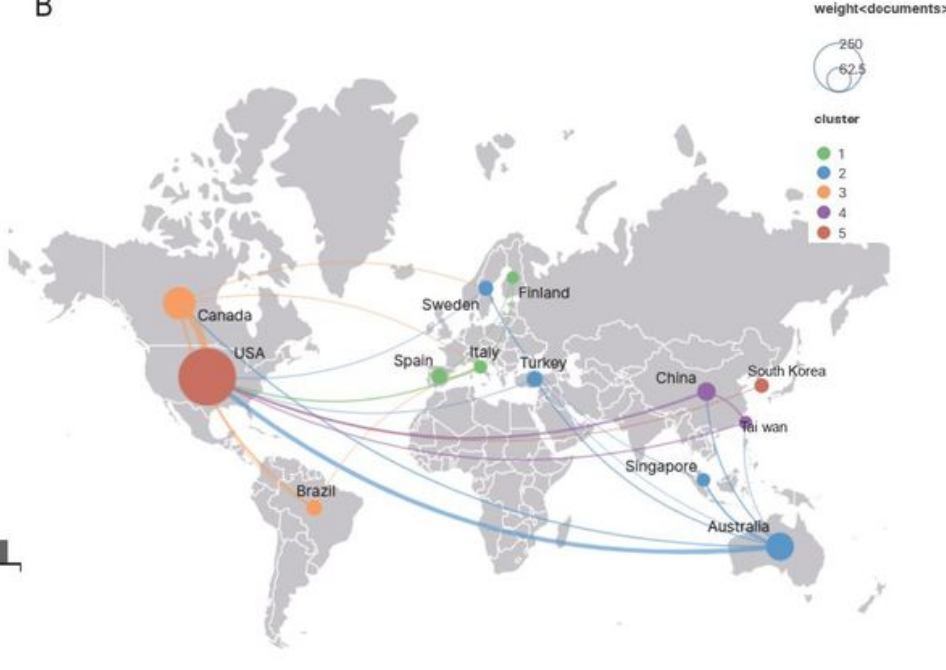

\section{Figure 4}

The top 10 prolific countries/regions and international collaborations on virtual simulation research in nursing. $(A)$ The number of publications, citation frequency $(\times 0.05)$, and $\mathrm{H}$-index $(\times 5)$ in top 10 countries/regions. (B) The co-authorship network visualization map of countries. Node size indicated the number of articles produced. The distance between any two nodes positively associated with the cooperation strength. The color indicated the average publication year for the author, Blue represents for early stage and yellow represents late stage. 
A

B
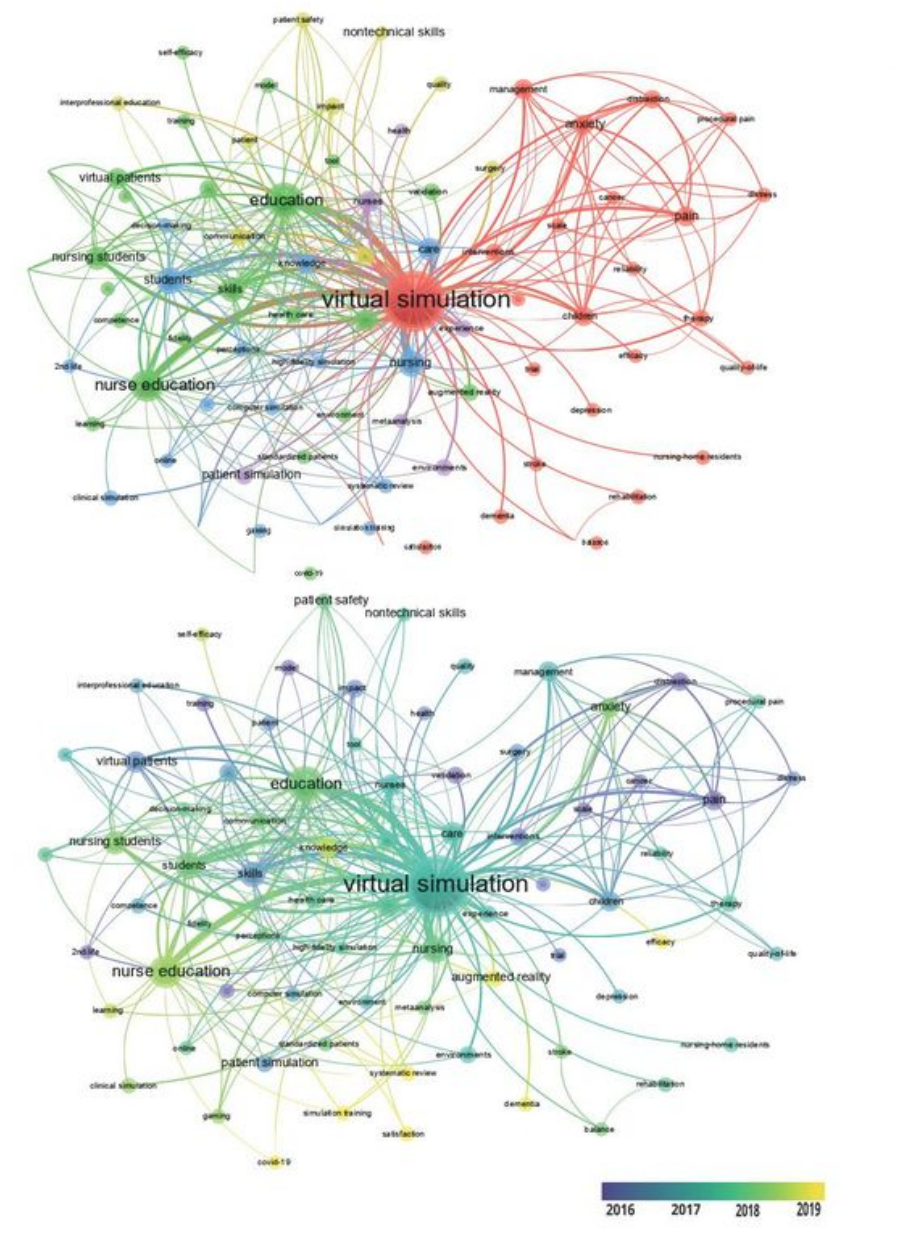

C

Top 19 Keywords with the Strongest Citation Bursts

\begin{tabular}{llrlll} 
Keywords & Year & Strength & Begin & End & $1999-2021$ \\
distraction & 1999 & 2.76 & 2004 & 2013 \\
adolescent & 1999 & 3.07 & 2007 & 2013 \\
model & 1999 & 2.89 & 2008 & 2014 \\
medical education & 1999 & 2.68 & 2009 & 2013 \\
virtual patient & 1999 & 4.09 & 2012 & 2019 \\
2nd life & 1999 & 3.76 & 2012 & 2014 \\
virtual world & 1999 & 3.18 & 2012 & 2015 \\
simulation & 1999 & 3.1 & 2013 & 2014 \\
disaster & 1999 & 2.91 & 2013 & 2016 \\
patient simulation & 1999 & 2.78 & 2013 & 2015 \\
second life & 1999 & 3.29 & 2014 & 2015 \\
virtual reality simulation & 1999 & 3.25 & 2014 & 2017 \\
nurse & 1999 & 3.25 & 2014 & 2017 \\
virtual environment & 1999 & 2.59 & 2014 & 2015 \\
program & 1999 & 3.54 & 2015 & 2018 \\
rehabilitation & 1999 & 3.42 & 2015 & 2018 \\
balance & 1999 & 2.97 & 2016 & 2017 \\
\hline nursing education & 1999 & 2.7 & 2019 & 2021 \\
reality & 1999 & 2.63 & 2019 & 2021 \\
\hline
\end{tabular}

\section{Figure 5}

Analysis of keywords related to publications of virtual simulation in nursing field. (A) The co-occurrence network visualization map of keywords. The keywords grouped into five clusters according to their color. Large nodes represented keywords with high frequency. (B) Keywords were colored according to the appearance for the average time. Blue represents for early stage and yellow represents more recently. (C) The top 19 keywords with strongest citation burst between 1999 and 2021. The red segment of the blue line denoted the burst duration of a keyword. 
A

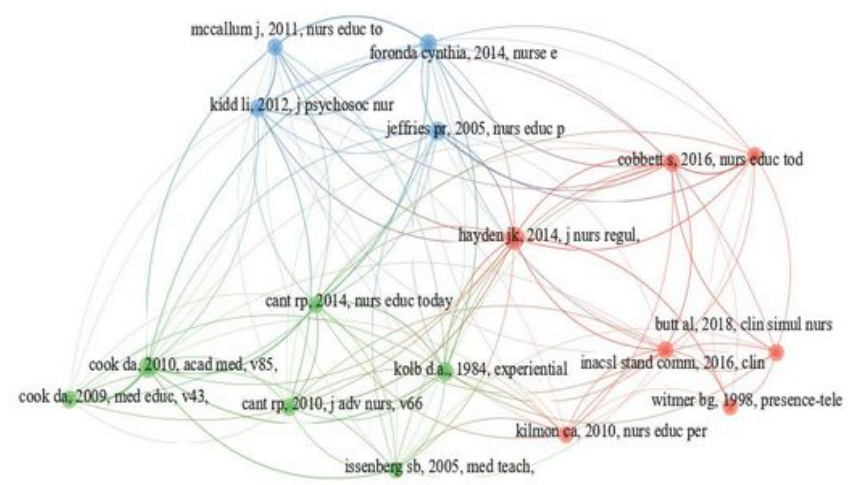

Vosviever
B

Top 23 References with the Strongest Citation Bursts

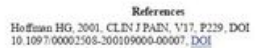

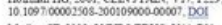

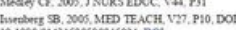
0.166001212590500046934 . DOA

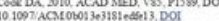

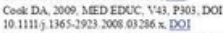

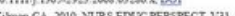

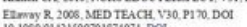
(1)

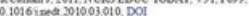

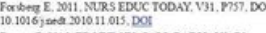

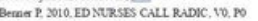
RidL1. 3012 JPSYCHOSOC NURS MEN , V50. P28,

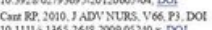

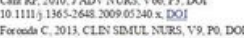
1. 1016;

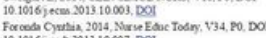
10. 1016 jent 201310007. DOA

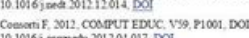

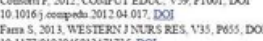

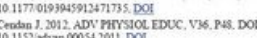

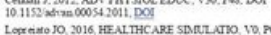

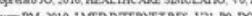
16219612959 , D DI

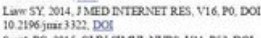

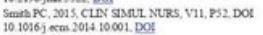

\section{Figure 6}

Analysis of most cited references and co-cited references of virtual simulation in nursing field. (A) The cocitation network visualization map of references between 1999 and 2021. (B) The top 23 references with the strongest citation burst between 1999 and 2021. The blue line represents the time from its first appearance to 2021, the red line represents the burst time.

\section{Supplementary Files}

This is a list of supplementary files associated with this preprint. Click to download.

- FigureS1.pdf 